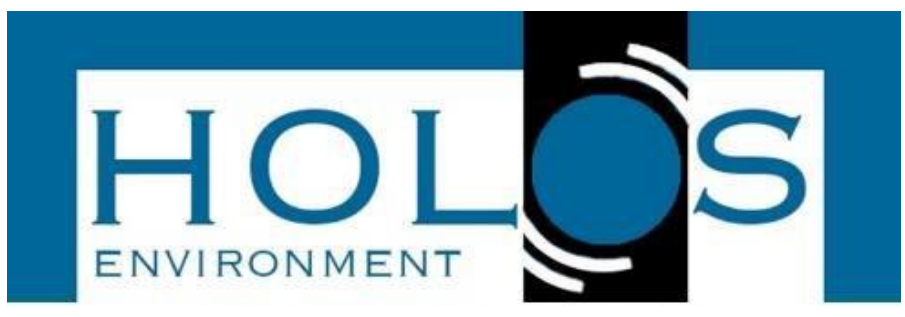

\title{
PERCEPÇÕES DE ALUNOS NO PROCESSO DE APRENDIZAGEM DO DESENVOLVIMENTO SUSTENTÁVEL EM CURSOS DE GRADUAÇÃO EM ADMINISTRAÇÃO E ADMINISTRAÇÃO PÚBLICA E SOCIAL
}

\section{PERCEPTIONS OF STUDENTS IN THE LEARNING PROCESS OF SUSTAINABLE DEVELOPMENT IN GRADUATE COURSES IN ADMINISTRATION AND PUBLIC AND SOCIAL ADMINISTRATION}

\author{
Cristiano Sordi Schiavi ${ }^{1}$; Mario Luiz Trevisan²
}

Artigo recebido em: 10/09/2019 e aceito para publicação em: 21/11/2019.

DOI: http://dx.doi.org/10.14295/holos.v19i4.12354

Resumo: Este artigo analisa a percepção de alunos no final dos cursos de graduação em Administração e Administração Pública Social com relação ao Desenvolvimento Sustentável, escolhendo como estudo de caso uma turma da disciplina de "Gestão Socioambiental nas Empresas" e uma turma da disciplina de "Gestão Socioambiental em Organizações Públicas e Sociais", na Escola de Administração, da Universidade Federal do Rio Grande do Sul. Por meio da metodologia qualitativa, a coleta de dados foi realizada sob a forma de questionário no primeiro semestre de 2018 , bem como foi feita a análise de conteúdo com a utilização do software Nvivo12 ${ }^{\circledR}$. $\mathrm{Na}$ análise das respostas dos alunos no final do curso, observou-se um olhar crítico com relação à sustentabilidade tanto no âmbito profissional quanto pessoal. Conclui-se que a educação ambiental torna-se cada vez mais fundamental na formação de profissionais e cidadãos críticos quanto à relação sociedade-natureza nos cursos de Administração, modificando as atitudes e comportamentos em prol do Desenvolvimento Sustentável.

Palavras-chave: Educação Ambiental. Desenvolvimento Sustentável. Administração.

\begin{abstract}
This article analyzes the perception of students at the end of undergraduate courses in Administration and Social Public Administration with regard to Sustainable Development, choosing as a case study a class of the discipline "Social and Environmental Management in Companies" and a class of the discipline "Social and Environmental Management in Public and Social Organizations", in the School of Administration, of Federal University of Rio Grande do Sul. Through the qualitative methodology, data collection was performed in the form of questionnaire in the first semester of 2018 and was made the content analysis using the Nviv012® software. In analyzing the responses of the students at the end of the course, there was a critical eye regarding sustainability both in the professional and personal. It is concluded that environmental education becomes increasingly important in the formation of professionals and critical citizens about the relationship between society and nature in Administration courses, changing attitudes and behavior in support of sustainable development.
\end{abstract}

Keywords: Environmental Education. Sustainable Development. Administration.

\footnotetext{
${ }^{1}$ Universidade Federal do Rio Grande do Sul (UFRGS), Porto Alegre, RS. E-mail: (cristianosordi@hotmail.com)

2 Universidade Federal de Santa Maria (UFSM), Santa Maria, RS. E-mail: (eletroduto@gmail.com)
} 


\section{INTRODUÇÃO}

A temática do Desenvolvimento Sustentável, alinhada ao ensino e aprendizagem da educação ambiental, pode promover uma reflexão da relação sociedade-natureza, com o intuito de superar a atual crise civilizacional. Isso é de fundamental importância, pois, de acordo com Leff (2006), a problemática ambiental surge como uma crise de civilização resultante da cultura ocidental, da racionalidade da modernidade, e da economia do mundo globalizado.

No campo da Administração, após a crise financeira global de 2008, Bajada e Trayler (2013) citam numerosos comentários acerca da necessidade de revisar a educação empresarial na direção de um currículo mais interdisciplinar, e também revigorar e incorporar a ética e a responsabilidade social corporativa no currículo para salvaguardar o futuro contra crises financeiras semelhantes. Thomas e Cornuel (2012) apontam também, na recente crise financeira, uma amplificação do debate público em blogs, jornais, mídia, etc. a respeito da proposição de valor nas escolas de Administração.

Para Thomas e Cornuel (2012), as escolas de Administração estão, definitivamente, em transição e em um ponto de virada em sua evolução e desenvolvimento; e um dos amplos temas para pensar sobre a evolução futura dos paradigmas das escolas de Administração envolve os impactos e influências ambientais na educação de gestão, incluindo questões de globalização, sustentabilidade global e avanços nas mídias digitais e sociais.

Segundo Jacobi, Raufflet e Arruda (2011), houve, nos últimos anos, um aumento de programas de graduação, pós-graduação e especialização em negócios que inseriram módulos, cursos e componentes de sustentabilidade em seus currículos. Para Jacobi, Raufflet e Arruda (2011), as propostas para a educação devem levar em consideração paradigmas que abordem a complexidade, na qual a sustentabilidade é vista como um novo critério básico e integrador, fortalecendo valores coletivos e solidários a partir de práticas educativas contextualizadoras e problematizadoras pautadas pelo paradigma da complexidade, aportando para a escola e para outros ambientes pedagógicos uma atitude de ação-reflexão-ação em torno da problemática ambiental.

Ademais, Jacobi, Raufflet e Arruda (2011) defendem que as práticas educativas ambientalmente sustentáveis apontem para propostas pedagógicas centradas na 
criticidade dos sujeitos, com o intuito de promover a mudança de comportamento e atitudes, o desenvolvimento da organização social e a participação coletiva. Um grande expoente da Teoria Pedagógica Crítica é Freire (1996), que assinala que uma das tarefas da prática educativa é o desenvolvimento da curiosidade crítica.

$\mathrm{Na}$ Escola de Administração da Universidade Federal do Rio Grande do Sul (UFRGS), os cursos de graduação em Administração e Administração Pública e Social possuem em sua grade curricular, respectivamente, as disciplinas de "Gestão Sócio- Ambiental nas Empresas" (Etapa 9 da Matriz Curricular) e "Gestão Socioambiental em Organizações Públicas e Sociais" (Etapa 7 da Matriz Curricular), abordando o Desenvolvimento Sustentável no ensino e aprendizagem no campo das organizações. No primeiro semestre de 2018, durante a realização do estágio docente supervisionado em uma turma de cada uma dessas disciplinas, surgiu como questão de pesquisa analisar as percepções de alunos no processo de ensino e aprendizagem do Desenvolvimento Sustentável, verificando se o conteúdo das disciplinas e as atividades realizadas podem levar a uma reflexão crítica dos alunos a respeito de valores éticos e de sustentabilidade na sua formação.

Dessa maneira, a pesquisa tem como objetivo analisar a percepção crítica de alunos no final do curso com relação ao Desenvolvimento Sustentável. Por meio do método qualitativo, foi realizado um estudo de caso, utilizando como técnica de pesquisa o questionário de perguntas abertas, com a coleta dos dados realizada durante o estágio docente. A estrutura da pesquisa está desenvolvida em cinco seções. Esta introdução (1), seguida da referencial teórico sobre o Desenvolvimento Sustentável, Educação Ambiental e o campo da Administração, assim como são tratados aspectos sobre a Teoria Pedagógica Crítica e a Aprendizagem Transformadora. A terceira e a quarta seções detalham o método (3) e os resultados e discussões da pesquisa (4). Na última seção, é apresentada a conclusão da pesquisa (5).

\section{REFERENCIAL TEÓRICO}

\subsection{Desenvolvimento sustentável e educação ambiental}

Segundo Lago (2013), a Conferência de Estocolmo (Conferência das Nações 
Unidas sobre Meio Ambiente Humano, 1972) foi a primeira grande reunião organizada pelas Nações Unidas concentrando-se sobre as questões de meio ambiente, como resultado da crescente atenção internacional para a preservação da natureza, e do descontentamento de diversos setores da sociedade quanto às repercussões da poluição sobre a qualidade de vida das populações.

Segundo Milaré (2013), após a Conferência sobre o Meio Ambiente Humano, reunida em Estocolmo, em 1972, grandes eventos sobre Educação Ambiental sob a égide das Nações Unidas inculcaram princípios e práticas a respeito da temática, tais como: a Conferência de Belgrado (1975); a Primeira Conferência Intergovernamental sobre Educação Ambiental, realizada em Tbilisi, Geórgia (unidade política da antiga União Soviética) em 1977; o Seminário sobre Educação Ambiental, na Costa Rica, 1979; o Congresso Internacional sobre Educação Ambiental e Formação Ambientais, em Moscou, no ano de 1987; e o Seminário Latino-Americano de Educação Ambiental, na Argentina, no ano de 1988.

No plano da legislação brasileira, um grande marco regulatório para as questões ambientais foi a Lei Federal no 6.938, de 31 de agosto de 1981, que dispõe sobre a Política Nacional do Meio Ambiente, seus fins e mecanismos de formulação e aplicação, e dá outras providências. Conforme destacado nos princípios da Política Nacional do Meio Ambiente, Art. $2^{\circ}$, inciso X, a educação ambiental assume uma importante missão para o cumprimento do objetivo dessa legislação, por meio da sua inserção em todos níveis de ensino, inclusive a educação da comunidade, permitindo o exercício ativo da cidadania em defesa do meio ambiente.

Tal reconhecimento é também instituído na Constituição Federal de 1988, em seu capítulo VI, do Meio Ambiente, com a promoção da educação ambiental pelo Poder Público, em todos os níveis de ensino. Ainda na década de 1980, cabe destacar o Relatório Nosso Futuro Comum e sua definição de desenvolvimento sustentável como o desenvolvimento que atende as necessidades atuais sem comprometer a habilidade das futuras gerações de atender suas próprias necessidades (ONU, 1987). Segundo Lago (2013), o Relatório da Comissão Mundial sobre Meio Ambiente e Desenvolvimento, conhecido também como Relatório Brundtland, foi um fator decisivo para a convocação de uma nova Conferência das Nações Unidas sobre meio ambiente.

Na década de 1990, então, ocorreu a Conferência do Rio (Conferência das Nações Unidas sobre Meio Ambiente e Desenvolvimento, também conhecida 
como ECO-92. A ECO-92 abordou também a educação ambiental no Capítulo 36 da Agenda 21 Global, intitulado Promoção do Ensino, da Conscientização e do Treinamento, no qual reconhece a importância do ensino para o desenvolvimento sustentável.

Segundo Milaré (2013), o campo de trabalho estava muito bem preparado para a Lei Federal n 9.795/1999, da Política Nacional de Educação Ambiental, sagrandose o País pioneiro na América Latina com a criação de uma política nacional específica para a educação ambiental. Conforme a Lei nำ 9.795/1999, em seu Art. 1ำ, a educação ambiental é entendida como os processos a partir dos quais "os indivíduos e a coletividade constroem valores sociais, conhecimentos, habilidades, atitudes e competências voltadas para a conservação do meio ambiente, bem de uso comum do povo, essencial a qualidade de vida e sua sustentabilidade".

Milaré (2013) destaca, no artigo 1ํㅡ, a relação entre a educação ambiental e a sustentabilidade, os vários processos envolvidos e a construção por parte da coletividade. Em relação aos princípios (Art. $4^{\circ}$ ), sublinha-se a concepção do meio ambiente em sua totalidade, levando em consideração a interdependência entre o meio natural, sócio-econômico e o cultural, sob o enfoque da sustentabilidade Inciso IV. Novamente, percebe-se na legislação brasileira a relação da educação ambiental com a sustentabilidade.

Em seu Art. $2^{2}$, a legislação estabelece a educação ambiental como um componente essencial e permanente da educação nacional, devendo estar presente de maneira articulada em todos os níveis e modalidades do processo educativo - em caráter formal e não-formal. Na seção 2 da Política Nacional de Educação Ambiental, o Art. 9º define a educação ambiental no ensino formal, englobando a educação superior.

Recentemente, no ano de 2015, foi aprovado o documento "Transformando o Nosso Mundo: a Agenda 2030 para o Desenvolvimento Sustentável”. Essa agenda contempla o legado dos Objetivos do Desenvolvimento do Milênio, cujos oitos objetivos deveriam ter sido contemplados até 2015, e busca tomar medidas ousadas e transformadoras para pôr o mundo em um caminho sustentável e resiliente com seus novos 17 objetivos globais e 169 metas (ONU, 2015). Destacase o Objetivo 4 dessa agenda, que busca assegurar a educação inclusiva e equitativa de qualidade, e pro- mover oportunidades de aprendizagem ao longo da vida para todos, e sua relação com o desenvolvimento sustentável (ONU, 2015). 


\subsection{Desenvolvimento sustentável e administração}

Na Resolução no 4, do Ministério da Educação, de 13 de julho de 2005, que institui as Diretrizes Curriculares do Curso de Graduação em Administração, bacharelado, e dá outras previdências, pode se constatar a ausência da temática do desenvolvimento sustentável. Embora não seja mencionada o desenvolvimento sustentável nos conteúdos de formação básica e profissional no Curso de Graduação em Administração, destaca-se que na formação complementar poderia incluir-se a temática, na tentativa de enxergar uma aproximação, uma vez que prevê estudos opcionais de caráter transversal e interdisciplinar.

Nas Diretrizes Curriculares para o Curso de Administração Pública - Resolução no 1, de 13 de Janeiro de 2014, do Ministério da Educação, também verifica-se a ausência da temática do desenvolvimento sustentável. De maneira similar ao currículo de graduação em Administração, pode-se constatar também a menção aos estudos de caráter transversal e interdisciplinar no curso de graduação em Administração Pública.

Bajada e Trayler (2013) e Thomas e Cornuel (2012) sugerem a integração no currículo da ética e da sustentabilidade no ensino do curso de Administração. Como mostrado por Bajada e Trayler (2013), é de extrema relevância a busca pela interdisciplinaridade nos cursos de Administração, inserindo a ética e sustentabilidade como um tema integrado comum no currículo. Segundo Amboni et al. (2012), nas últimas décadas a interdisciplinaridade vem sendo discutida por autores de diversas áreas do conhecimento a fim de tentar romper as fronteiras da disciplinaridade. Um dos grandes questionadores do saber fragmentado é Morin (2000), que defende a necessidade de uma visão complexa para um conhecimento pertinente capaz de apreender os objetos em seu contexto, complexidade, e conjunto, substituindo a supremacia do conhecimento fragmentado de acordo com as disciplinas que impede de operar o vínculo entre as partes e a totalidade.

Sobre a interdisciplinaridade, Jacobi, Raufflet e Arruda (2011) apontam que as experiências e práticas educativas e de pesquisa interdisciplinares ainda são recentes e incipientes. Para uma proposta de educação em direção a paradigmas que abordem a complexidade, segundo Jacobi, Raufflet e Arruda (2011), os processos de conhecimento fundamentam-se em cortes transversais na compreensão e explicação dos contextos de aprendizagem e de formação, com o estímulo voltado 
para a interação e a interdependência entre as disciplinas e, consequentemente, entre as pessoas para o desenvolvimento de metodologias interativas.

Tal premissa de interdisciplinaridade (interdependência entre o meio natural, o socioeconômico e o cultural, sob o enfoque humanista, democrático e participativo) é um dos princípios da educação ambiental, conforme a Resolução no 2, de 15 de junho de 2012, que estabelece as Diretrizes Curriculares para a Educação Ambiental. Quanto à inserção do Desenvolvimento Sustentável nas Escolas de Administração, Jacobi, Raufflet e Arruda (2011) refletem a respeito de como a sustentabilidade é apresentada nos cursos, com 0 ensino de Administração que enfatiza significativamente a prática, exemplificando com as teorias relacionadas à Corporate Social Responsability e ao Desenvolvimento Sustentável que não deixa de espelhar essa tradição de internalização da área, resultante hoje da pressão de governos e sociedades para que as empresas sejam responsabilizadas por seu impacto ambiental, econômico e social.

Entretanto, Jacobi, Raufflet e Arruda (2011) criticam os paradigmas incrementais e adaptativos associados ao ensino da sustentabilidade nas escolas de Administração, cujo foco está voltado ao treinamento de futuros administradores para que trabalhem em direção a um aumento da eficiência e da geração de inovações incrementais, trabalhando muito pouco para instigar os estudantes a repensar e a desafiar o sistema mais amplo de produção, em seu contexto ecológico-social. Por outro lado, Jacobi, Raufflet e Arruda (2011) sugerem um outro caminho além do treinamento gerencial, educando indivíduos responsáveis e comprometidos com a sustentabilidade, em razão dos desafios que a humanidade vem enfrentando e enfrentará, representando uma carga de responsabilidade para o ensino da Administração do século XXI e um convite para se reinventar.

\subsection{Teoria pedagógica crítica}

No modelo da pedagogia diretiva, caracterizado pelo mito da transmissão do conhecimento, e seu pressuposto epistemológico que vê o sujeito como uma folha de papel em branco totalmente determinado pelo mundo do objeto ou pelos meios físico e social, o ensino e aprendizagem são polos dicotômicos, com o professor jamais aprendendo e o aluno jamais ensinando, sendo, assim, o modelo, por excelência do fixismo, da reprodução, da repetição (BECKER, 1994). 
Já no modelo da pedagogia não-diretiva, o professor é um auxiliar do aluno, um facilitador, e em seu pressuposto epistemológico apriorista o professor renuncia seu papel na intervenção do processo de aprendizagem do aluno, numa relação na qual o polo do ensino é desautorizado, e o da aprendizagem é tornado absoluto (BECKER, 1994).

Por sua vez, na pedagogia relacional, o professor construtivista acredita que tudo o que o aluno construiu até hoje em sua vida serve de patamar para construir e que alguma porta abrirá para o aluno construir algum conhecimento novo, e seu pressuposto epistemológico também relacional pode ser uma alternativa para superar a disciplina policialesca e a figura autoritária do professor que a representa, e, por outro lado, a de ultrapassar o dogmatismo do conteúdo (BECKER, 1994). Desse modo, cabe mencionar no final do artigo o questionamento de Becker (1994) a respeito de que cidadão o professor quer que seu aluno seja.

Conforme Barbosa e Moura (2013), a aprendizagem ativa ocorre quando o aluno interage com o assunto em estudo (ouvindo, falando, perguntando, discutindo, fazendo e ensinando), estimulado a construir seu conhecimento em vez de recebê-lo de forma passiva. Nessa perspectiva, o professor não é apenas a única fonte de informação e conhecimento, atuando como orientador, supervisor, facilitador do processo de aprendizagem (BARBOSA, MOURA, 2013).

Na obra de Freire (1996), intitulada "Pedagogia da Autonomia", o professor tem um papel-chave na construção do conhecimento, somado à participação dos alunos nesse processo. Um dos grandes expoentes da Teoria Pedagógica Crítica, Freire (1996) afirma que ensinar exige compreender que a educação é uma forma de intervenção no mundo. Segundo Guimarães (2004), a educação ambiental crítica tem como objetivo a promoção de ambientes de mobilização de processos de intervenção sobre a realidade e seus problemas socioambientais, superando armadilhas paradigmáticas e propiciando um processo educativo, em que nesse exercício, educandos e educadores, possam exercer uma cidadania ativa na transformação da crise socioambiental vivenciada por todos.

\section{MÉTODO}

O presente artigo emprega uma abordagem qualitativa para analisar a percepção dos alunos no processo de ensino e aprendizagem do 
Desenvolvimento Sustentável nos cursos de graduação em Administração e Administração Pública e Social. Assim, adotou-se o estudo de caso para a realização da pesquisa, escolhendo duas turmas das disciplinas presenciais de graduação "Gestão Sócio-Ambiental nas Empresas" (Etapa 9 da Matriz Curricular do Curso de Graduação em Administração) e "Gestão Socioambiental em Organizações Públicas e Sociais" (Etapa 7 da Matriz Curricular do Curso de Graduação em Administração Pública e Social) - da Escola de Administração da UFRGS, na cidade de Porto AlegreRS, uma vez que tais disciplinas abordam o conceito do Desenvolvimento Sustentável em suas ementas, e devido à acessibilidade do autor da pesquisa para realizar os estágios docentes nessa instituição de ensino. Para Yin (2015), o estudo de caso, como esforço de pesquisa, contribui de forma singular na compreensão de fenômenos individuais, organizacionais, sociais e políticos.

Após a definição da unidade de análise do estudo de caso, partiu-se para a coleta de dados. No final da disciplina, foi aplicado um questionário de perguntas abertas aos alunos das disciplinas "Gestão Sócio-Ambiental nas Empresas" e "Gestão Socioambiental em Organizações Públicas e Sociais", uma vez que todos os conteúdos da disciplina já tinham sido trabalhados em sala de aula com os alunos. Quanto tal técnica de coleta de dados, Gerhardt et al. (2009, p. 69) afirma que a mesma objetiva "levantar opiniões, crenças, sentimentos, interesses, expectativas, situações vivenciadas”.

Sobre o processo de elaboração do questionário, Gerhardt et al. (2009) define que nas questões abertas o informante responde livremente, da forma que desejar. Dessa maneira, foram elaboradas duas perguntas: (1) "qual sua visão hoje a respeito das questões que envolvem a temática da sustentabilidade na sua formação profissional / pessoal?"; (2) "as atividades realizadas, os conceitos vistos e reflexões em sala de aula ajudaram a olhar de uma maneira diferente?". Apesar de apenas duas perguntas, buscou-se, através do seu caráter aberto, proporcionar uma liberdade para os alunos expressarem suas percepções em diferentes direções.

Na disciplina "Gestão Sócio-Ambiental nas Empresas", do curso de graduação em Administração, 21 questionários foram respondidos de um total de 40 alunos matriculados. Já na disciplina "Gestão Socioambiental em Organizações Públicas e Sociais", do curso de graduação em Administração Pública e Social, 16 questionários foram respondidos de um total de 26 alunos matriculados. Desse modo, no total, foram analisados 37 questionários na pesquisa. 
Após a coleta de dados, foi realizada sua análise, utilizando o software Nvivo12® (2018) para verificar os principais termos que os alunos utilizaram em suas respostas, a partir da análise de frequência e da ilustração de nuvens de palavras. Também foi realizada análise de conteúdo desses termos mais frequentes na nuvem de palavras. Dessa forma, os códigos de análise inicial foram constituídos a partir das perguntas realizadas e já as categorias intermediárias e finais emergiram das respostas dadas a essas perguntas elaboradas, em razão da possibilidade dos alunos poderem interpretar e argumentar sobre o conteúdo de forma aberta. Segundo Schreier (2013), a análise dos dados por meio de análise conteúdo busca descrever o significado dos dados qualitativos ao atribuir categorias para o material coletado em um quadro de codificação que apresenta todos os aspectos de descrição e interpretação.

\section{RESULTADOS E DISCUSSÕES}

As Figuras 1 e 2 ilustram as palavras mais identificadas nas respostas dos alunos das disciplinas "Gestão Sócio-Ambiental nas Empresas" e "Gestão Socioambiental em Organizações Públicas e Sociais", respectivamente, para a primeira questão, através do software Nvivo12 ${ }^{\circledR}$. Cabe destacar que as nuvens de palavras foram elaboradas exibindo as 25 palavras mais frequentes, com comprimento mínimo de quatro letras e agrupamento com palavras derivadas. Ademais, palavras consideradas não relevantes para a análise foram adicionadas para a lista de palavras impedidas.

Figura 1 - Nuvem de palavras da Questão 1 - "Gestão Sócio-Ambiental nas Empresas"

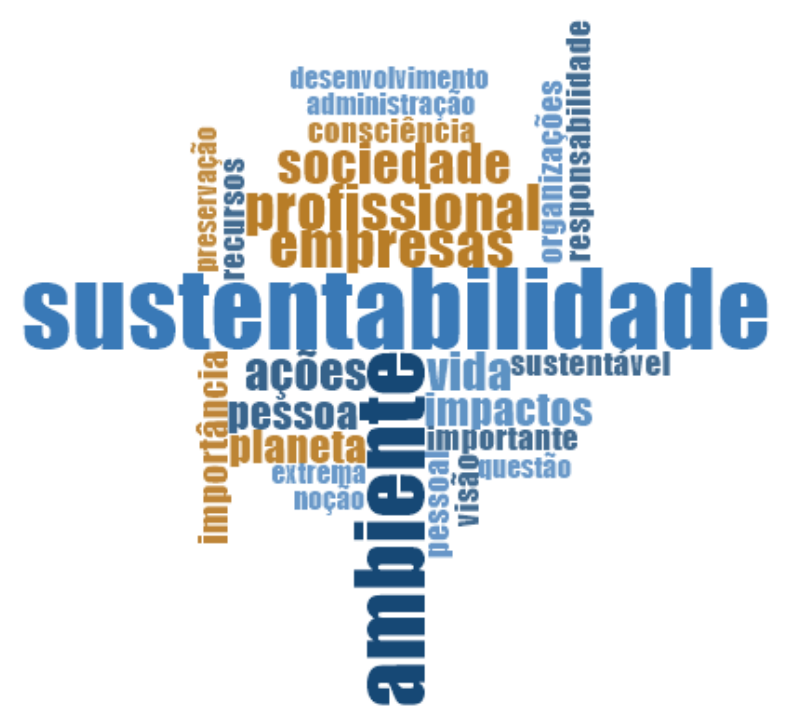

Fonte: Dados da pesquisa (2018) 
Figura 2 - Nuvem de palavras da Questão 1 - "Gestão Socioambiental em Organizações Públicas e Sociais"

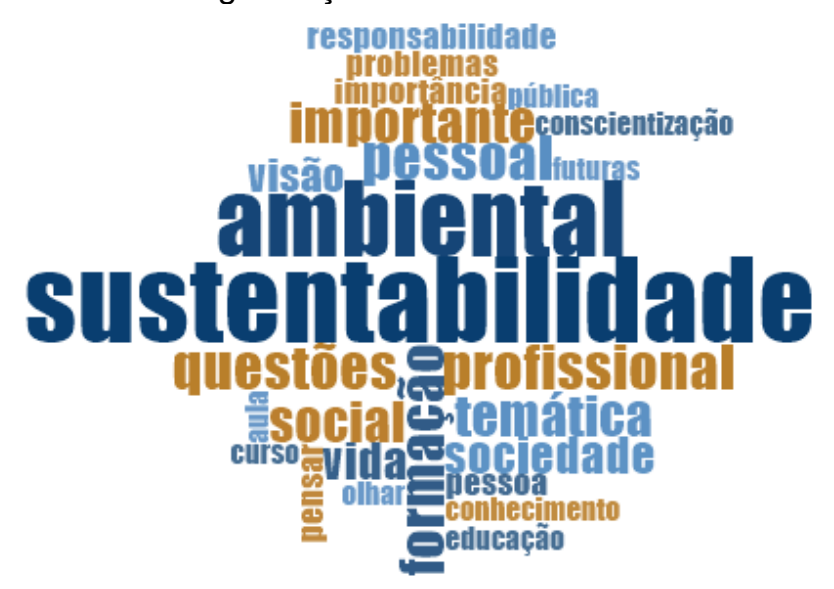

Fonte: Dados da pesquisa (2018)

As palavras mais ressaltadas nas respostas na Figura 1 foram "sustentabilidade”, "ambiente”, “empresas", "profissional”, "sociedade”, “ações”, "vida”, "impactos", "pessoa", "planeta", "importância" e "consciência". Já na Figura 2, destacam-se as palavras "sustentabilidade", "ambiental", "formação", "pessoal", "profissional", "questões", "social", "temática", "importante", "sociedade", "vida" e "visão".

Com relação aos alunos do curso de graduação em Administração, pode se observar em suas respostas da Questão 1 a utilização das palavras "consciência", "importância", "importante", "responsabilidade" relacionadas com "sustentabilidade", "ambiente", tanto no âmbito "pessoal" quanto "profissional" / "empresas" / "organizações", demandando uma reflexão sobre as "ações" coletivas, individuais e do profissional em Administração.

Sobre as respostas dos alunos do curso de graduação em Administração Pública e Social, pode se notar a utilização das palavras "conscientização", "importância", "importante", "visão", "responsabilidade", relacionadas com "sustentabilidade", "ambiental", tanto no âmbito "pessoal" quanto "profissional", demandando uma reflexão ("pensar", "olhar") na "formação" do Administrador Público e Social.

A partir da análise da questão 1, nota-se a importância de discutir a temática do Desenvolvimento Sustentável a partir de um paradigma complexo e crítico, enfatizando suas múltiplas dimensões de análise, em consonância com a Teoria Pedagógica Crítica e a Complexidade. Conforme Jacobi, Raufflet e Arruda (2011), não se deve ensinar os alunos apenas a trabalharem com o foco no treinamento de 
futuros administradores na direção a um aumento da eficiência e da geração de inovações incrementais nas organizações, mas também instigando os estudantes a repensar e a desafiar o sistema mais amplo de produção, em seu contexto ecológico-social. Dessa maneira, buscou-se, nas disciplinas, mostrar diferentes visões da gestão socioambiental além do treinamento gerencial, educando os alunos para tornarem-se profissionais e cidadãos críticos, responsáveis e comprometidos com o Desenvolvimento Sustentável.

As Figuras 3 e 4 ilustram as palavras mais identificadas nas respostas dos alunos das disciplinas "Gestão Sócio-Ambiental nas Empresas" e "Gestão Socioambiental em Organizações Públicas e Sociais”, respectivamente, para a segunda questão, por meio do software Nvivo12ß. Novamente, as nuvens de palavras foram elaboradas exibindo as 25 palavras mais frequentes, com comprimento mínimo de quatro letras e agrupamento com palavras derivadas, desconsiderando palavras não relevantes para a análise que foram adicionadas para a lista de palavras impedidas.

Figura 3 - Nuvem de palavras da Questão 2 - "Gestão Sócio-Ambiental nas Empresas"

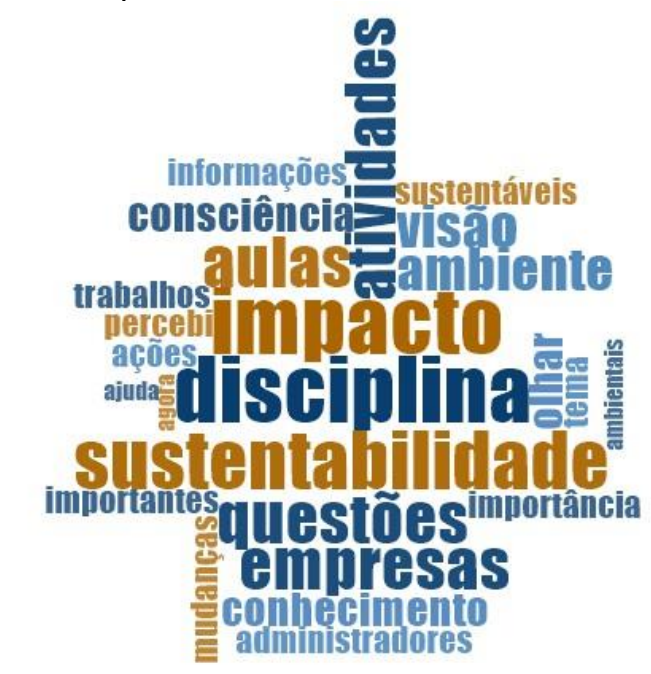

Fonte: Dados da pesquisa (2018)

As palavras que mais se sobressaíram nas respostas na Figura 3 foram "disciplina", "impacto", "sustentabilidade", "atividades", "aulas", "empresas", "questões", "ambiente", "visão", "consciência", "olhar" e "administradores". Já na Figura 4, distinguiram-se as palavras "ambiental", "aula", "questões", "disciplina", "questão", "atividades", "conceitos", "olhar", "sociedade", "sustentabilidade", "ajudaram" e "conhecimento". 
Figura 4 - Nuvem de palavras da Questão 2 - "Gestão Socioambiental em Organizações Públicas e Sociais"

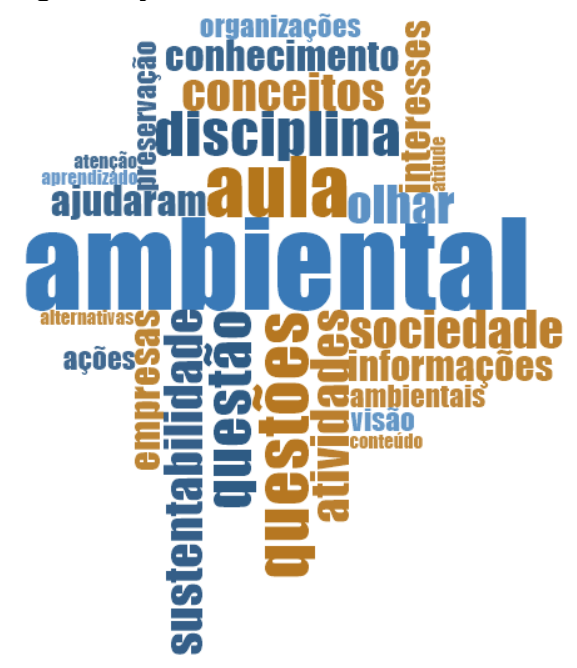

Fonte: Dados da pesquisa (2018)

No que se refere aos alunos do curso de graduação em Administração, pode se observar em suas respostas na Questão 2 a utilização das palavras "consciência", "importância", “importantes", "conhecimento", "olhar", “ações”, “informações”, "mudanças", "visão", "impacto", que denotam a capacidade crítica dos alunos de lidar na "disciplina" com as "questões" que envolvem as temáticas "sustentabilidade" / "ambiente", por meio das "atividades" propostas nas "aulas".

Quanto aos alunos do curso de graduação em Administração Pública e Social, a utilização das palavras "ajudaram", "importantes", "conhecimento", "olhar", "interesses", "ações”, "informações” vão ao encontro do saber necessário para tratar também criticamente as diversas "questões" discutidas a respeito da "sustentabilidade" / "ambiental" na "disciplina".

Ao longo do semestre, procurou-se através dos processos de ensino e aprendizagem despertar o olhar crítico profissional e de cidadania para as questões ambientais e do desenvolvimento sustentável, afastando-se do que Jacobi, Raufflet e Arruda (2011) criticam em relação a abordagem tradicional da sustentabilidade no curso de Administração, com o foco apenas sob a ótica gerencial.

Para identificar as respostas dos alunos das disciplinas "Gestão Sócio-Ambiental nas Empresas" e "Gestão Socioambiental em Organizações Públicas e Sociais", foram utilizados os códigos ADME_a e ADMP_a, respectivamente. Já para identificar as respostas da segunda questão dos alunos das disciplinas "Gestão Sócio-Ambiental nas Empresas" e "Gestão Socioambiental em Organizações Públicas e Sociais" foram utilizados os códigos ADME_b e ADMP_b, respectivamente. 
Com relação às metodologias ativas de aprendizagem, foram observados alguns comentários referentes às atividades desenvolvidas em sala de aula, bem como sugestões de outras atividades nas respostas da Questão 2.

Tivemos algumas apresentações dos colegas que foram muito relevantes a respeito de acontecimentos e iniciativas que buscam melhorar a nossa realidade ou que trouxeram grandes impactos para a sociedade. (ADME2_b)

As atividades realizadas foram de grande importância. Observar fenômenos que há não muito tempo pareciam distantes e que agora fazem parte dos desafios dos administradores moderno, mais do que uma ação positiva é uma necessidade latente. (ADME4_b)

Sim, pois agora temos um maior embasamento sobre essas questões. Além de, com os trabalhos apresentados e aulas, tivemos contato com assuntos e questões que não são tratados comumente. (ADME7_b)

Sim, certamente as atividades realizadas ao longo do semestre abriram minha cabeça para novas ideias e para novas formas de olhar uma empresa. Entendi que existem novas tendências no mundo às quais podemos aproveitar em nossas vidas e empresas, como a do Slow Food, por exemplo. A disciplina agregou bastante ao meu conhecimento holístico, de uma visão sistêmica. (ADME10_b)

As referências apresentadas em aula com certeza ampliaram meu horizonte nesse campo. Principalmente as informações de caráter prático. (ADME18_b)

A vivência que tive com a disciplina e os debates em sala de aula ajudaram a perceber o que nós deixamos com nossa vida para as futuras gerações. (ADMP2_b)

(...) Ter tido a oportunidade de assistir documentários que mostram realidades de como o meio ambiente sofre com a poluição foi de grande valia. Os documentários fazem ter mais consciência de que é preciso cuidar do meio ambiente. (ADMP5_b)

(...) algumas atividades trouxeram pontos que desconhecia além de movimentos sociais super interessantes. Gostaria que a gente pudesse ver na prática a aplicação de mudanças sustentáveis nas empresas, através de uma visitação ou até testemunho. (ADME1_b)

Destaca-se, na proposição das metodologias ativas empregadas nas disciplinas, a construção do conhecimento através dos debates em sala de aula, propiciados por meio da aula expositiva dialogada e da apresentação dos seminários e filmes ao longo do semestre, que procuravam contextualizar os conceitos teóricos vistos na disciplina com situações práticas e atuais. Cabe destacar também a possibilidade de empregar mais metodologias ativas de aprendizagem como, por exemplo, a visita técnica, sugerida por um dos alunos.

Por fim, são realçadas algumas respostas dos alunos que enfatizaram a importância da educação ambiental e do ensino do Desenvolvimento Sustentável 
no currículo da Administração, bem como a necessidade de aprimorar o currículo do curso no caminho da interdisciplinaridade.

Considero ainda precárias as discussões sobre sustentabilidade ambiental nos cursos de formação profissional para administradores. Sustentabilidade deveria se um dever de todos na visão de negócios que envolvam também questões de comportamento social em relação ao tema. (...) (ADMP4_a)

(...) A educação ambiental também deveria ser melhor trabalhada nas instituições de ensino, porque antes dessa cadeira nenhum professor da faculdade tinha abordado o assunto. E foi somente por meio dessas aulas que descobri muitas ações, iniciativas e empresas que trabalham com o conceito de sustentabilidade. (...) (ADME5_a)

(...) ainda acho deficiente a formação oferecida no curso de Administração quanto a esse aspecto. Apenas uma cadeira sobre o tema parece ser pouco para discutir esse tema e principalmente pensar novas práticas que ajudem a mudar o rumo de meio ambiente que vivemos. (ADMP7_a)

Acredito que a disciplina ajudou a amadurecer alguns conceitos e achava importante que todos estudantes deveriam ter a oportunidade de estudar essas questões, em grupos, pois o debate é muito importante e acrescenta mais conteúdo. Muitas vezes pensamos questões ambientais apenas a partir das consequências de desastres ambientais mas pensar em sustentabilidade é muito mais que isso. Vários problemas sociais são interligados e, para mim, pensar sustentabilidade quer dizer pensar nesses problemas em rede (...) (ADMP11_a)

Gostei da disciplina e acho que ela é muito importante para a formação dos administradores. Pena que é apenas uma e uma das últimas do semestre. (ADME17_b)

Até o momento não havia estudado uma disciplina que abordasse tão a fundo esses conceitos de sustentabilidade. Normalmente as visões estratégicas para o curso de administradores abordam teorias conceituais a parte da preservação ambiental. (ADMP4_b)

Como observado nas respostas dos alunos, as disciplinas de "Gestão SócioAmbiental nas Empresas" e "Gestão Socioambiental em Organizações Públicas e Sociais" encontram-se no final curso, impossibilitando que os alunos tenham um contato com a temática ambiental e do Desenvolvimento Sustentável desde seu ingresso no curso. Ademais, a fragmentação de disciplinas no currículo e a dificuldade de conexões entre as mesmas acabam por prejudicar a aprendizagem dos alunos. Cabe destacar aqui a proposição de Bajada e Trayler (2013) que insere a ética e sustentabilidade como um tema integrado comum no currículo. Assim, a educação ambiental e o ensino do Desenvolvimento Sustentável no curso de graduação em Administração e Administração Pública e Social requerem uma reestruturação dos currículos na direção da interdisciplinaridade. 


\section{CONCLUSÃO}

No contexto atual de uma crise civilizacional, torna-se cada vez mais necessário repensar criticamente a relação sociedade-natureza. Para isso, a educação ambiental pode propiciar aos alunos uma formação comprometida com as questões éticas, em consonância com os pressupostos do Desenvolvimento Sustentável.

No campo da administração, os profissionais não podem estar alheios às discussões atuais de sustentabilidade. Pelo contrário, os egressos devem estar preparados para lidar com os diversos desafios ambientais encontrados nas organizações, com uma postura crítica comprometida com os valores que embasam o desenvolvimento sustentável.

A presente pesquisa procurou analisar a percepção de alunos no processo de ensino e aprendizagem do Desenvolvimento Sustentável em duas turmas das disciplinas de graduação em "Gestão Sócio-Ambiental nas Empresas" (Etapa 9 da Matriz Curricular do Curso de Graduação em Administração) e "Gestão Socioambiental em Organizações Públicas e Sociais" (Etapa 7 da Matriz Curricular do Curso de Graduação em Administração Pública e Social), da Escola de Administração da UFRGS, no primeiro semestre de 2018.

Por meio da análise das respostas dos alunos no final do curso, pode-se notar um olhar crítico dos mesmos com relação à sustentabilidade tanto como profissional quanto cidadão. Ademais, as atividades empregadas citadas pelos alunos (aula expositiva dialogada, da apresentação dos seminários e filmes ao longo do semestre, e estudo dirigido) ajudaram na construção do conhecimento, contextualizando os conceitos teóricos vistos na disciplina com situações práticas e atuais. Embora tenhase observado na discussão inicial que os alunos não tinham um aprofundamento teórico a respeito da temática e desconheciam a sua importância no contexto das organizações, aponta-se como limitação da pesquisa o fato de não ter sido aplicado o questionário também no começo do semestre.

Finalmente, destaca-se a necessidade premente de integrar as questões éticas e do Desenvolvimento Sustentável de uma maneira interdisciplinar e transversal no currículo dos cursos de Administração e Administração Pública e Social, fomentando o debate durante toda a graduação. Desse modo, a educação ambiental, alinhada aos

pressupostos do Desenvolvimento Sustentável, deve ser um elemento-chave do currículo, contribuindo na formação de profissionais e cidadãos críticos. 


\section{REFERÊNCIAS}

AMBONI, N.; ANDRADE, R.; LIMA, A.; MULLER, I. Interdisciplinaridade e complexidade no curso de graduação em Administração. Cad. EBAPE.BR, Rio de Janeiro, v. 10, n. 2, p. 302328, June 2012.

BAJADA, C.; TRAYLER, R. Interdisciplinary business education: curriculum through collaboration. Education + Training, v. 55 n. 4/5 p. 385 - 402, 2013.

BARBOSA, E. F.; MOURA, D. G. Metodologias ativas de aprendizagem na Educação Profissional e Tecnológica. Boletim Técnico do Senac, Rio de Janeiro, v. 39, n.2, p.48-67, maio/ago. 2013.

BECKER, F. Modelos pedagógicos e modelos epistemológicos. Educação e Realidade, v.19, n.1, 1994.

BRASIL. Lei n.o 6.938, de 31 de agosto de 1981. Disponível em: http://www.planalto.gov.br/ccivil 03/Leis/L6938.htm. Acesso em: 15 nov. 2018.

BRASIL. Constituição da República Federativa do Brasil: promulgada em 5 de outubro de 1988. Disponível em: http://www.planalto.gov.br/ccivil 03/Constituicao/Constituicao.htm. Acesso em: 15 nov. 2018.

BRASIL. Lei no 9.795, de 27 de abril de 1999. Disponível em: http://www.planalto.gov.br/ccivil 03/leis/L9795.htm. Acesso em: 15 nov. 2018.

BRASIL. Ministério da Educação. Resolução № 4, de 13 de julho de 2005. Disponível em: http://portal.mec.gov.br/cne/arquivos/pdf/rces004 05.pdf. Acesso em: 15 nov. 2018.

BRASIL. Ministério da Educação. Resolução № 1, de 13 de janeiro de 2014. Disponível em: http://portal.mec.gov.br/index.php?option=com docman\&view=download\&alias=14957rces001-14\&ltemid=30192f. Acesso em: 15 nov. 2018.

FREIRE, P. Pedagogia da autonomia: saberes necessários à prática educativa. São Paulo: Paz e Terra, 1996.

GERHARDT, I.; RAMOS, I.; RIQUINHO, D.; SANTOS, D. Estrutura do Projeto de pesquisa. In. GERHARDT, T.; SILVEIRA, D. Métodos de Pesquisa. Porto Alegre: Editora da UFRGS, 2009.

GUIMARÃES, M. Educação ambiental crítica. In: MINISTÉRIO DO MEIO AMBIENTE. Identidade da educação ambiental brasileira. Org. Philippe Layrargues. Brasília, 2004. P.25- 34 .

JACOBI, P.; RAUFFLET, E.; ARRUDA, M. Educação para sustentabilidade nos cursos de administração: reflexão sobre paradigmas e práticas. Revista de Administração

Mackenzie, São Paulo, v. 12, n. 3. edição especial, p. 21-49, maio/jun. 2011.

LAGO, A. Conferências do desenvolvimento sustentável. Brasília: FUNAG, 2013. 200p.

LEFF, E. Racionalidade ambiental: a reapropriação social da natureza / Enrique Leff; tradução Luís Carlos Cabral. - Rio de Janeiro: Civilização Brasileira, 2006. 
MILARÉ, É. Direito do ambiente. 8. ed. rev., atual., e ampl. São Paulo: Editora Revista dos Tribunais, 2013.

MORIN, E. Os sete saberes necessários à educação do futuro. São Paulo: Cortez, 2000. 118p.

NVIVO12. NVivo qualitative data analysis Software. QSR International Pty Ltd. Version 12, 2018.

ORGANIZAÇÃO DAS NAÇÕES UNIDAS - ONU. Our common future. 1987. Disponível em: http://www.un-documents.net/our-common-future.pdf. Acesso em: 15 nov. 2018.

ORGANIZAÇÃO DAS NAÇÕES UNIDAS - ONU. Agenda 21 Global. 1992. Disponível em: http://www.mma.gov.br/estruturas/agenda21/ arquivos/cap36.pdf. Acesso em: 15 nov. 2015.

ORGANIZAÇÃO DAS NAÇÕES UNIDAS - ONU. Transformando nosso mundo: a Agenda 2030 para o desenvolvimento sustentável. 2015. Disponível em: http://www.br.undp.org/content/dam/brazil/docs/agenda2030/undp-br-Agenda2030-completo-pt-br-2016.pdf. Acesso em: 15 nov. 2018.

SCHREIER, M. Qualitative content analysis. In: FLICK, U. (Ed.). The Sage handbook of qualitative data analysis. London: Sage, 2013, p. 170-183.

THOMAS, H.; CORNUEL, E. Business schools in transition? Issues of impact, legitimacy, capabilities and re-invention. Journal of Management Development, v. 31, n.4, 2012, p. 329- 335.

YIN, Robert K. Estudo de caso: planejamento e métodos. 5. ed. Porto Alegre: Bookman, 2015. 